Cite this: Phys. Chem. Chem. Phys., 2013,

\title{
Dynamic nuclear polarization of spherical nanoparticles $\dagger$
}

15, 20706

Received 2nd September 2013,

Accepted 9th October 2013

DOI: $10.1039 / \mathrm{c} 3 \mathrm{cp} 53095 \mathrm{~g}$

www.rsc.org/pccp

\author{
Ümit Akbey, ${ }^{\text {a }}$ Burcu Altin, ${ }^{\mathrm{b}}$ Arne Linden, ${ }^{\mathrm{a}}$ Serdar Özçelik, ${ }^{\mathrm{c}}$ Michael Gradzielskib \\ and Hartmut Oschkinat ${ }^{a}$
}

Spherical silica nanoparticles of various particle sizes ( 10 to $100 \mathrm{~nm})$, produced by a modified Stoeber method employing amino acids as catalysts, are investigated using Dynamic Nuclear Polarization (DNP) enhanced Nuclear Magnetic Resonance (NMR) spectroscopy. This study includes ultra-sensitive detection of surface-bound amino acids and their supramolecular organization in trace amounts, exploiting the increase in NMR sensitivity of up to three orders of magnitude via DNP. Moreover, the nature of the silicon nuclei on the surface and the bulk silicon nuclei in the core (sub-surface) is characterized at atomic resolution. Thereby, we obtain unique insights into the surface chemistry of these nanoparticles, which might result in improving their rational design as required for promising applications, e.g. as catalysts or imaging contrast agents. The non-covalent binding of amino acids to surfaces was determined which shows that the amino acids not just function as catalysts but become incorporated into the nanoparticles during the formation process. As a result only three distinct Q-types of silica signals were observed from surface and core regions. We observed dramatic changes of DNP enhancements as a function of particle size, and very small particles (which suit in vivo applications better) were hyperpolarized with the best efficiency. Nearly one order of magnitude larger DNP enhancement was observed for nanoparticles with $13 \mathrm{~nm}$ size compared to particles with $100 \mathrm{~nm}$ size. We determined an approximate DNP penetration-depth $(\sim 4.2$ or $\sim 5.7 \mathrm{~nm})$ for the polarization transfer from electrons to the nuclei of the spherical nanoparticles. Faster DNP polarization buildup was observed for larger nanoparticles. Efficient hyperpolarization of such nanoparticles, as achieved in this work, can be utilized in applications such as magnetic resonance imaging (MRI).

\section{A Introduction}

DNP increases the sensitivity of NMR experiments (signal-to-noise ratio, $\mathrm{S} / \mathrm{N}),{ }^{1-3}$ enabling the study of low concentrated systems

\footnotetext{
${ }^{a}$ Leibniz-Institut für Molekulare Pharmakologie (FMP),

NMR Supported Structural Biology, Robert-Rössle-Str. 10, 13125 Berlin, Germany. E-mail: akbey@fmp-berlin.de; Fax: +4930 94793169; Tel: +493094793238

${ }^{b}$ Technische Universität Berlin, Institut für Chemie, Straße des 17. Juni 124, 10623 Berlin, Germany

${ }^{c}$ Izmir Institute of Technology Department of Chemistry, 35430 Gulbahce, Urla, Izmir, Turkey

† Electronic supplementary information (ESI) available: Synthesis and physical characterization of the nanoparticles (SI 1); ${ }^{13} \mathrm{C} \mathrm{CP},{ }^{29} \mathrm{Si} \mathrm{CP}$ and ${ }^{29} \mathrm{Si}$ directexcitation MAS NMR spectra of the non-coated silica particle (SI 2); the integral fits of the ${ }^{29} \mathrm{Si}$ NMR spectra for different sites (SI 3); the relative and absolute ${ }^{1} \mathrm{H} /{ }^{29} \mathrm{Si}$ DNP enhancements of a $11 \mathrm{~nm}$ arginine surface functional nanoparticle (SI 4); the relaxation delay dependent lineshape of ${ }^{29} \mathrm{Si}$ (SI 5); the ${ }^{13} \mathrm{C}$ CPMAS spectra of the nanoparticles with 25 and $90 \mathrm{~nm}$ particle sizes (SI 6); and details of the calculation of the total surface area, total TOTAPOL molecule per unit surface, and the percentages of the polarized/non-polarized parts of the nanoparticles (SI 7). See DOI: 10.1039/c3cp53095g
}

which were not in the scope of NMR until now. NMR signal enhancement is achieved by transferring large electron polarization to surrounding nuclei via DNP. In the last decade, there has been remarkable progress in solution and solid-state DNP-NMR as well as in imaging through the application of hyperpolarization methods. ${ }^{4-7}$ As pointed out recently, this "renaissance of DNP" combined with high magnetic fields will further grow in the coming years, enabling demanding applications with better resolution. ${ }^{8,9}$ Materials and biological systems such as membrane or microcrystalline proteins,${ }^{10-13}$ fibrils, ${ }^{14}$ ligands bound to receptors, ${ }^{15}$ polymers, ${ }^{16-18}$ surface-bound species, ${ }^{19-23}$ and other low concentrated samples were studied beneficially using DNP-NMR. ${ }^{13,24-26}$ Cryogenic temperatures are required to slow down nuclear and electron relaxation and to allow an efficient polarization transfer in solid-state DNP NMR experiments. In contrast to biological systems, ${ }^{15,27-29}$ most technically relevant materials do not show detrimental lines broadening at low temperatures.

Hence, several successful applications of solid-state DNPNMR to materials were reported including fast and sensitive characterization of catalyst surfaces and bulk species as well as 
Table 1 DNP enhancements $(\varepsilon)$ and build-up-times $\left(t_{\mathrm{B}}\right)$ are given for proton and silicon magnetization for nanoparticles with diameters between 13 and $100 \mathrm{~nm}$. The silicon sites are represented by the resonances of $\delta\left(\mathrm{Q}_{2}\right)=-90, \delta\left(\mathrm{Q}_{3}\right)=-100$ and $\delta\left(\mathrm{Q}_{4}\right)=-110 \mathrm{ppm}$. The DNP enhancements for different silicon sites were determined by comparing the $\mu \mathrm{W}$ on and off spectra under otherwise identical conditions, and by comparing the intensity increase through DNP. The DNP polarization buildup times were determined by a saturation recovery experiment under simultaneous $\mu \mathrm{W}$ irradiation. The ${ }^{1} \mathrm{H}$ enhancements and buildup times were determined using a ${ }^{29} \mathrm{Si}$ CP MAS NMR experiment, whereas, the ${ }^{29} \mathrm{Si}$ values were measured via direct-excitation MAS NMR. A slow and a fast component was detected in the ${ }^{29} \mathrm{Si}$ DNP buildup curve, by fitting the values shown in Fig. 6 to a bi-exponential function; $I_{t}=I_{0}\left[(1-x)\left(1-\exp \left(-t / \tau_{\text {Fast }}\right)\right)+x\left(1-\exp \left(-t / \tau_{\text {Slow }}\right)\right)\right]$, where $\tau_{\text {Fast }}$ and $\tau_{\text {Slow }}$ are the fast and slow DNP buildup constants, and $x$ is the ratio between the fast and slow components. The proton buildup curves were fitted by a mono-exponential function. The particle diameters were determined from DLS measurements (see ESI 1 for details, as well as BET surface areas). The $100 \mathrm{~nm}$ particle is a pure silica nanoparticle without surface coating, whereas, all other particles are coated with arginine. The samples were prepared with 20 mM TOTAPOL concentration except for the N-A90 (5 mM) sample which has $5 \mathrm{mM}$ radical

\begin{tabular}{|c|c|c|c|c|c|c|c|c|c|}
\hline & $\begin{array}{l}\text { Particle diameter } \\
(\mathrm{nm})\end{array}$ & $\begin{array}{l}\varepsilon_{1 \mathrm{H}}^{\mathrm{MAS}} \\
\text { Water/TEOS }\end{array}$ & $\begin{array}{l}\varepsilon_{29}^{\mathrm{CP}} \mathrm{Si} \\
\mathrm{Q}_{3}\end{array}$ & $\begin{array}{l}\varepsilon_{29}^{\mathrm{MAS}} \\
\mathrm{Q}_{2}\end{array}$ & $\begin{array}{l}\varepsilon_{29}^{\mathrm{MAS}} \\
\mathrm{Q}_{3}\end{array}$ & $\begin{array}{l}\varepsilon_{29}^{\mathrm{MAS}} \\
\mathrm{Q}_{4}\end{array}$ & $\tau_{\mathrm{B}}^{1} \mathrm{H}$ & $\begin{array}{l}\tau_{\mathrm{B}-\mathrm{Si} \mathrm{Q}_{4}}^{29} \\
(\sim 70 \%)\end{array}$ & $\begin{array}{l}\tau_{\mathrm{B}-\mathrm{Fast}}^{29} \mathrm{Si} \mathrm{Q}_{4} \\
(\sim 30 \%)\end{array}$ \\
\hline $\mathrm{N}-100$ Pure $\mathrm{SiO}_{2}$ & 100 & 13 & 4 & 1 & 2 & 3 & 5.0 & 613 & 11 \\
\hline N-A90 & 90 & $24 / 9$ & 6 & 2 & 5 & 7 & 4.8 & 626 & 26 \\
\hline N-A62 & 62 & 31 & 11 & 3 & 6 & 9 & 3.7 & 774 & 41 \\
\hline N-A51 & 51 & 31 & 15 & 3 & 7 & 10 & 3.0 & 766 & 39 \\
\hline N-A31 & 31 & 36 & 28 & 5 & 11 & 17 & 2.6 & 917 & 66 \\
\hline N-A25 & 25 & 37 & 39 & 7 & 15 & 20 & 2.2 & 887 & 45 \\
\hline N-A13 & 13 & 46 & 43 & 6 & 13 & 21 & 2.0 & 981 & 66 \\
\hline N-A90 (5 mM) & 90 & $32 / 6.5$ & 8 & 2 & 4 & 5 & 4.8 & 1036 & 60 \\
\hline
\end{tabular}

polymers. A first example of "surface-enhanced DNP-NMR" provided by Lesage et al., ${ }^{19}$ revealed surface bound aromatic substrates on mesoporous silicon-oxide materials at natural abundance. For this purpose, the solvent protons were first polarized by DNP, which was subsequently transferred to rare carbon nuclei. A 50-fold signal enhancement was observed. In a later work by Lelli $e t$ al., surface silicon sites were characterized using ${ }^{29} \mathrm{Si}$ cross-polarization (CP)-MAS DNP-NMR and incipient wetness impregnation of the samples with radical-containing solvents. ${ }^{20}$ This work shows that the functional groups on catalyst surfaces can fold back rather than pointing into the core cavities. Later, Lafon et al. demonstrated the characterization of bulk silica sites buried beneath the surfaces in a similar porous material by using direct excitation ${ }^{29} \mathrm{Si}$ DNP-NMR. ${ }^{21}$ Rossini et al. showed that the surface sites in small pores, from which the radical is excluded, can be hyperpolarized using DNP NMR methods on functionalized metal-organic frameworks. ${ }^{22}$ Furthermore, intrinsic (endogenous) spin labels in polymers enable DNPNMR without the necessity of supplying exogenous radicals. ${ }^{18}$ Compared to other methods, such as surface enhanced Raman spectroscopy, ${ }^{30,31}$ DNP-NMR can give better information about molecular interactions, packing, and $\operatorname{order}^{32}$ and therefore unique information with almost atomic resolution.

Nanoparticles have attracted great attention in many fields due to their variable and often superior physico-chemical properties compared to materials with the same chemical structure but larger size. ${ }^{33-38}$ These properties depend on the particle size which needs to be controlled for promising applications, such as in imaging as better contrast agents or for better bio-dispersity (for less toxicity in vivo). ${ }^{39-43}$ Particularly, bio-inspired (amino acid or peptide functional) nanoparticles result in self-assembled and structure-directed materials with a controlled particle size. ${ }^{44}$ In addition, the surface structure of nanoparticles is of central importance as their properties are largely controlled by their large relative interfacial area. Functional and well-defined silica nanospheres have been successfully synthesized using a modified Stöber method introduced by Yokoi et al. to include arginine or lysine on surfaces, with particle sizes changing between $\sim 10$ and $100 \mathrm{~nm}$ with a well-ordered internal structure (SI 1, ESI $\dagger$ the synthesis and the physical characterization of the materials. See Table 1 for the list of studied particles). ${ }^{44,45}$ These materials have a similar chemical structure as, e.g. mesoporous bulk materials, but with better properties due to their decreased size and increased surface area. Especially, correlating molecular level site-specific knowledge about the surface and bulk regions of these nanomaterials will clarify remaining questions on their activity and function. As a result, solid-state DNP-NMR is indispensable for understanding the details of structure-function-property relationships. Previously, conventional $\left({ }^{1} \mathrm{H},{ }^{13} \mathrm{C}\right.$ or $\left.{ }^{31} \mathrm{P}\right)$ NMR studies have been performed on spherical nanoparticles and mesoporous materials, however, suffering from low sensitivity. ${ }^{46-50}$ Very recently, application of DNP enhanced MAS NMR spectroscopy on several nanoparticles has been demonstrated, showing the feasibility of the technique for studying such systems. ${ }^{51-53}$

Here we apply MAS DNP-NMR spectroscopy to investigate site-specific surface and bulk properties of pure (non-functional) as well as arginine- and lysine-functionalized silicon-oxide nanoparticles (Fig. 1).$^{44}$ Precise knowledge of the surface composition and chemistry of such nanoparticles is essential for rationalizing their behavior, especially concerning their interactions with biomolecules or membranes, and so far such knowledge is still limited. The natural abundance nuclei at the molecular sites (proton, carbon, and silicon) have been characterized by DNPNMR exploiting signal enhancements $(\varepsilon)$ of up to $\sim 50$ and $\sim 20$ for protons and silicon, respectively. The efficiency of DNP-NMR experiments depends strongly on the nanoparticle size $(\sim 10$ to $100 \mathrm{~nm})$, which needs to be fine-tuned for optimized DNP properties. ${ }^{44,54}$ The $\mathrm{Q}_{2}, \mathrm{Q}_{3}$ and $\mathrm{Q}_{4}$ types of surface silica species were characterized and surface binding of arginine and lysine were determined to be via non-covalent supramolecular interactions. These results reveal the details of the molecular structure of nanoparticles and the mechanism of polarization transfer between the hyperpolarized nuclei on the 


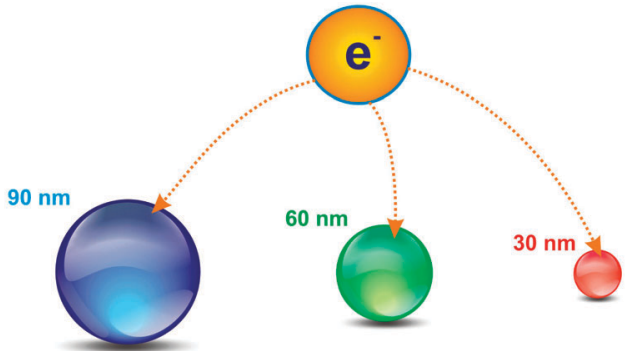

Silica Nanoparticles
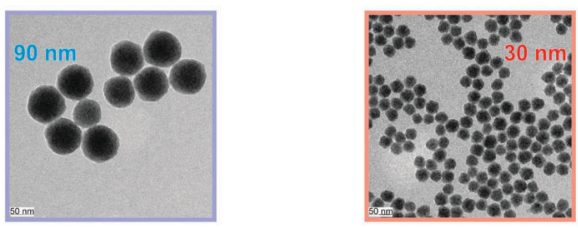

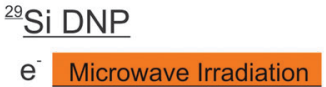

${ }^{1} \mathrm{H}$ Decouple

${ }^{29} \mathrm{Si}$ Recycle Delay

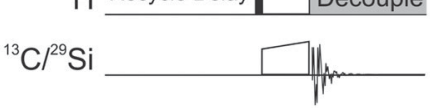

Fig. 1 Representation of the DNP enhanced solid-state NMR spectroscopy of nanoparticles. Different nanoparticle sizes are shown with different colors and sizes of spheres. The pulse sequences used for the characterization are given below. The direct excitation and cross-polarization types of ${ }^{13} \mathrm{C} /{ }^{29} \mathrm{Si}$ MAS NMR experiments were performed using DNP, which gives site specific information about the surface coated surfactants (arginine or lysine in the current case), and surface or bulk parts of the nanoparticle. The TEM images for the two nanoparticles with 30 and $90 \mathrm{~nm}$ particle sizes are shown as an example.

surfaces to the bulk nuclei inside the nanoparticles. Such information is important for understanding the properties of such nanoparticles and a major aim of this article is to explore the potential of DNP-NMR to obtain additional information.

\section{B Materials and methods}

\section{Nanoparticle synthesis}

The nanoparticle synthesis is described in detail in SI 1a, ESI. $†$

\section{Characterization of nanoparticle physical properties}

The nanoparticles were characterized by means of dynamic light scattering (DLS) and transmission electron microscopy (TEM). The corresponding data are presented and explained in SI $1 \mathrm{~b}$ and c, ESI. $\nmid$ It should be noted that all nanoparticles employed were very well-defined in terms of size, with polydispersity indices well below 0.1 (see Table S1, ESI $\dagger$ ).

\section{DNP enhanced solid-state NMR}

All the DNP-NMR experiments with magic angle spinning were performed on a commercial Bruker DNP spectrometer operating at $400 \mathrm{MHz}{ }^{1} \mathrm{H}$ Larmor frequency. A continuous wave $263 \mathrm{GHz}$ microwave irradiation was generated using the Bruker gyrotron of up to several watts. A triple resonance HCN DNP probe using
$3.2 \mathrm{~mm}$ rotor (zirconium oxide) was used. The experiments were performed at $\sim 100 \mathrm{~K}$ controlled by a Bruker low-temperature unit. The DNP-NMR samples were prepared by dissolving-immersing

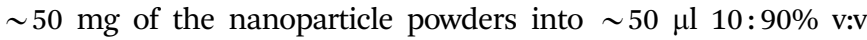
$\mathrm{H}_{2} \mathrm{O}: \mathrm{D}_{2} \mathrm{O}$ solution containing $20 \mathrm{mM}$ TOTAPOL concentration. No glycerol was used. The rotors were filled fully with as much material as possible ( $\sim 30$ to $50 \mathrm{mg}$ in total). The NMR experiments were performed by using $5 \mu$ s pulses for $\pi / 2$ excitation. For the ${ }^{13} \mathrm{C}$ and ${ }^{29} \mathrm{Si} \mathrm{CP}$ experiments the heteronucleus $\left({ }^{13} \mathrm{C} /{ }^{15} \mathrm{~N}\right)$ spin-lock pulse RF was set to $\sim 50 \mathrm{kHz}$ and the proton spin-lock $\mathrm{RF}$ was adjusted such that the +1 Hartman-Hahn matching condition was obtained at either 8 or $12 \mathrm{kHz}$ MAS with a $75-100 \%$ ramp on the proton shape-pulse. 0.4 or $3 \mathrm{~ms} \mathrm{CP}$ contact times were used for the ${ }^{13} \mathrm{C}$ or ${ }^{29} \mathrm{Si} \mathrm{CP}$ NMR experiments. $\sim 100$ TPPM proton decoupling was applied for all experiments. The DNP polarization buildup times were obtained by using saturation recovery pulse sequences (for proton via ${ }^{29} \mathrm{Si} \mathrm{CP}$ and for silicon via ${ }^{29} \mathrm{Si}$ direct-excitation) under continuous $\mu \mathrm{W}$ irradiation.

\section{Results and discussion}

\section{D DNP enhanced ${ }^{13} \mathrm{C} \&{ }^{29} \mathrm{Si}$ MAS NMR spectra}

The NMR spectra were recorded with ${ }^{13} \mathrm{C}$ or ${ }^{29} \mathrm{Si} \mathrm{CP}$ as well as ${ }^{29} \mathrm{Si}$ direct-excitation, by using the pulse sequences shown in Fig. 1. The spectra were recorded with and without microwave $(\mu \mathrm{W})$ irradiation to demonstrate signal enhancement obtained by DNP (Table 1). The solid-state DNP-NMR spectra of arginineand lysine-functionalized silica nanoparticles with a size of $\sim 25 \mathrm{~nm}$. $20 \mathrm{mM}$ TOTAPOL radical was used for the DNP experiments (dissolved in 10:90\% $\mathrm{H}_{2} \mathrm{O}-\mathrm{D}_{2} \mathrm{O}$, v:v) in samples prepared by “incipient wetness impregnation" (Fig. 2). ${ }^{19,55}$ DNP enhancements of $\sim 20$ and $\sim 37$ were observed for silicon and proton nuclei, respectively, for the particle size of $25 \mathrm{~nm}$. Such very small silica nanoparticles are interesting as they have been shown to penetrate phospholipid membranes rather easily and can be chemically modified in order to optimize such transport further and to be versatile carrier particles. ${ }^{56}$ These values are similar to the ones reported previously. ${ }^{19}$ However, $\sim 30 \%$ larger enhancements were observed for direct-excitation ${ }^{29} \mathrm{Si}$ DNP experiments recently by using a different microwave $(\mu \mathrm{W})$ irradiation frequency, under the so-called "_" DNP condition (at $\omega_{e}+\omega_{n}$ ), instead of the "+" DNP condition (at $\omega_{e}-\omega_{n}$ ) used. ${ }^{21}$

The power of the DNP enhancements leads to the observation of spectra with high sensitivity in a very short experiment time $(\sim 60$ or $\sim 40$ seconds for the $1 \mathrm{D}$ CP or direct-excitation experiments, respectively, for experimental parameters see the caption of Fig. 2). This is dramatically facilitating multidimensional NMR experiments at natural abundance for site specific assignments. The spectra recorded without DNP show only very weak signals within the same experiment time. In general, three different regions in the studied nanoparticles can be distinguished:

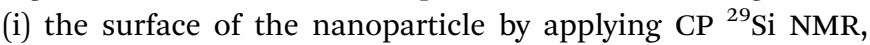
(ii) the core (sub-surface) of the nanoparticle through directexcitation ${ }^{29} \mathrm{Si} \mathrm{NMR}$, and (iii) the surface bound arginine and 

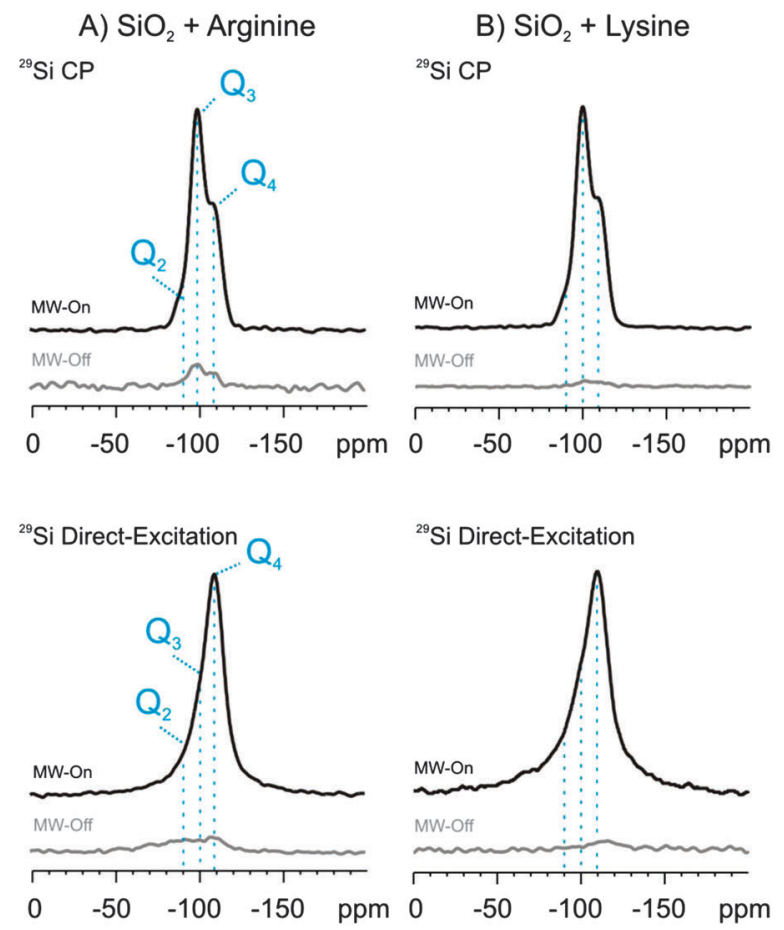

${ }^{13} \mathrm{C} \mathrm{CP}$
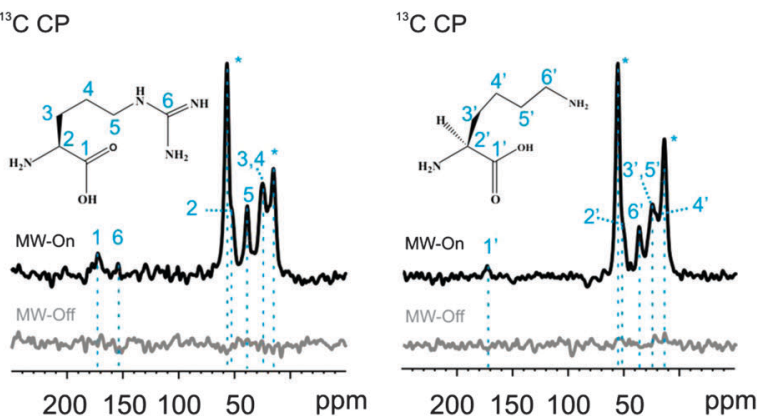

Fig. 2 The DNP enhanced $1 \mathrm{D}{ }^{13} \mathrm{C} \mathrm{CP}$ and ${ }^{29} \mathrm{Si}$ direct-excitation/CP NMR spectra of arginine- (A) and lysine- (B) functionalized silicon-oxide nanoparticles with $\sim 25 \mathrm{~nm}$ particle size. The spectra recorded with and without DNP are shown in black and grey colors, respectively, at 8 (for ${ }^{29} \mathrm{Si}$ ) or 12 (for ${ }^{13} \mathrm{C}$ ) $\mathrm{kHz} \mathrm{MAS}$ and $\sim 100 \mathrm{~K}$. The ${ }^{13} \mathrm{C} \mathrm{CP},{ }^{29} \mathrm{Si}$ direct-excitation and ${ }^{29} \mathrm{Si} \mathrm{CP}$ NMR spectra were recorded with 1024, 32 and 4 scans, respectively, similarly for the $\mu \mathrm{W}$ on and off experiments. Relaxation delays of 2 and 10 seconds were used for the $\mathrm{CP}$ and direct-excitation type experiments, respectively. Contact times of 0.4 and $3 \mathrm{~ms}$ for the ${ }^{13} \mathrm{C}$ and ${ }^{29} \mathrm{Si}$ CP NMR experiments. The carbon signals from residual TEOS are indicated by asterisks.

lysine by $\mathrm{CP}{ }^{13} \mathrm{C}$ NMR experiments. Separate surface and bulk characterization studies were performed recently by using ${ }^{29} \mathrm{Si}$ MAS or CP DNP, ${ }^{20,21}$ which we combine here with the ${ }^{13} \mathrm{C} \mathrm{CP}$ DNP experiment to obtain a better picture of the nanoparticle structure and polarization transfer properties of such spherical nanoparticles. ${ }^{19}$

The ${ }^{29} \mathrm{Si}$ CP spectra show different Q-type $\left(\mathrm{Q}_{n}=\mathrm{Si}\right.$ $\left.(\mathrm{OSi})_{n}(\mathrm{OH})_{4-n}\right)$ silicon sites for both coated and pure silica materials, which are observed at $\delta_{29}^{\mathrm{Q}_{4}}=\sim 110, \delta_{29}^{\mathrm{Q}_{3}}=\sim 100$, and $\delta_{29}^{\mathrm{Q}_{2}}=\sim 90 \mathrm{ppm}$ (see SI 2 , ESI $\dagger$ for $1 \mathrm{D}^{13} \mathrm{C}$ and ${ }^{29} \mathrm{Si}$ spectra of non-functional silicon-oxide nanoparticles). ${ }^{19,21}$ The amount of different silicon sites are determined by integrating the specific resonances in spectra recorded via CP (represented below in terms of ratios, \%, in each individual spectrum. The differences in those individual ratios between different samples are compared); which are 10/8 $\left(\mathrm{Q}_{2}\right), 57 / 71\left(\mathrm{Q}_{3}\right)$, and 33/21 $\left(\mathrm{Q}_{4}\right) \%$ for the 25/100 $\mathrm{nm}$ nanoparticles coated with arginine, respectively (the ratios and some of the fits are in SI 3, ESI, $\uparrow$ as well as for other particles). A remarkable observation is that no $\mathrm{Q}_{2}$ type silicon site was detected in conventional ${ }^{29}$ Si MAS NMR experiments for similar nanoparticles studied previously, but only the $\mathrm{Q}_{3}$ and $\mathrm{Q}_{4}$ sites were identified. ${ }^{44}$ The $\mathrm{Q}_{2}$ type silicon sites are determined to be $\sim 10 \%$ in $\mathrm{CP}$ based spectra (Fig. 2), which clearly proves the power of the DNP-NMR technique in the determination of chemically different sites on surfaces at low concentrations and natural abundance. No T-type silicon sites are observed $\left(\mathrm{T}_{n}=\mathrm{Si} \mathrm{R}(\mathrm{OX})_{3-n}(\mathrm{OSi})_{n}\right.$, surface silicon sites with a chemically bound functional group; $\mathrm{R}$ and $\mathrm{X}$ are organic functional sites) using ${ }^{29} \mathrm{Si}$ CP DNP-NMR experiments (Fig. 2A and B), indicating that the arginine/lysine binds to the nanoparticle surface with supramolecular interactions such as hydrogen bonding or electrostatic forces, but not via chemical bonds as observed for other mesoporous silica materials. ${ }^{20}$

An interesting behavior appears when the CP (indirect DNP) and direct-excitation (direct DNP) ${ }^{29} \mathrm{Si}$ spectra are compared (Fig. 2). All three silicon sites $\left(\mathrm{Q}_{2-4}\right)$, are polarized via $\mathrm{CP}$ $\left(\varepsilon_{\mathrm{Q}_{2}}^{29} \mathrm{Si}=\sim 35 / 3, \varepsilon_{\mathrm{Q}_{3}}^{29}=\sim 39 / 4\right.$, and $\varepsilon_{\mathrm{Q}_{4}}^{29}=\sim 35 / 5$ for the $25 / 100 \mathrm{~nm}$ nanoparticles, respectively). Direct-excitation, however, results in spectra with dominating $\mathrm{Q}_{4}$ type of silicon signals with high enhancement. Whereas, the $\mathrm{Q}_{2}$ and $\mathrm{Q}_{3}$ signals are present in the direct excitation ${ }^{29} \mathrm{Si}$ spectra with less intensity due to a less efficient polarization with much lower enhancements compared to $\mathrm{Q}_{4}$ enhancements (Table 1). This difference between the direct-excitation and $\mathrm{CP}{ }^{29} \mathrm{Si}$ DNP experiments has been reported previously for a mesoporous silica material, ${ }^{21}$ which shows that the surface silicon sites $\left(\mathrm{Q}_{2-3}\right)$ are best polarized by $\mathrm{CP}$, whereas, the sub-surface sites $\left(\mathrm{Q}_{4}\right)$ are polarized by directexcitation, which is also the case for the studied nanoparticles. As a result, it can be concluded that there is a preferential DNP polarization phenomenon in both silica based mesoporous and spherical materials, which leads to different DNP enhancements for different ${ }^{29} \mathrm{Si}$ sites, and as a result, different signal intensities in the spectra. This observation is difficult to rationalize since the $\mathrm{Q}_{2}$ and $\mathrm{Q}_{3}$ sites are very close to the surface or they are on the surface, and as a result they are closer to the radicals compared to $\mathrm{Q}_{4}$. However, because of a possible larger amount of $\mathrm{Q}_{4}$ nuclei present in the polarizable region of the nanoparticles, the signals appear much more intense than the signals of other sites in the ${ }^{29} \mathrm{Si}$ MAS NMR spectrum. The localization of the radical on the nanoparticle surface can also lead to the bleaching of silicon signals close to the radical, which might result in the observed less intense $\mathrm{Q}_{2}$ and $\mathrm{Q}_{3}$ signals. ${ }^{28}$ The ${ }^{29}$ Si MAS NMR spectra recorded without $\mu \mathrm{W}$ irradiation are similar in signal intensity, indicating the absence of any significant bleaching effect.

Determination of the absolute DNP enhancements were done on one of the nanoparticles, to estimate the real signal enhancement by DNP NMR at $\sim 100 \mathrm{~K}$ with radicals compared 
to a sample without radicals and measured at ambient temperature. For this purpose, $11 \mathrm{~nm}$ arginine surface functional nanoparticles were used. The comparison of the $\mu \mathrm{W}$-on ${ }^{29} \mathrm{Si}$ CPMAS and MAS spectra recorded at $100 \mathrm{~K}$ to the $\mu \mathrm{W}$-off spectra recorded at $100 \mathrm{~K}$ resulted in DNP enhancements of $43\left({ }^{1} \mathrm{H} \mathrm{DNP}\right)$ and $14\left({ }^{29} \mathrm{Si} \mathrm{DNP}\right)$ for this specific nanoparticle preparation. And finally, for the determination of absolute DNP enhancements, we compared the $\mu \mathrm{W}$-on ${ }^{29} \mathrm{Si}$ CPMAS and MAS spectra recorded at $100 \mathrm{~K}$ to the spectra recorded at $280 \mathrm{~K}$ but without radicals. The results show that the DNP enhancements are $18\left({ }^{1} \mathrm{H} \mathrm{DNP}\right)$ and $26\left({ }^{29} \mathrm{Si} \mathrm{DNP}\right)$, which shows that the absolute ${ }^{1} \mathrm{H}$ DNP enhancement is nearly half of the direct-comparison ( $\mu \mathrm{W}$ on/off) value, whereas, the ${ }^{29} \mathrm{Si} \mathrm{DNP}$ enhancement is nearly two times larger indicating the favored shorter relaxation times due to the presence of radicals (SI 4, ESI $\dagger$ ). Similar comparisons were done on other silica materials as well. ${ }^{52,57}$

\section{The effect of nanoparticle size \& composition of Si-sites}

After determination of the enhancement of each type of signal, we investigated the nanoparticle-size-dependent changes in the surface/sub-surface silicon hyperpolarization ratios by comparing the signals observed from the DNP enhanced ${ }^{29} \mathrm{Si}$ CP spectra particles with different sizes applying 5 and $20 \mathrm{mM}$ radicals (SI 3, ESI $\dagger$ ). The integral of the whole spectrum is normalized to $100 \%$, to be able to compare the signal intensity changes among different spectra. In the $25 \mathrm{~nm}$ particle coated with arginine, the signals of $\mathrm{Q}_{2}, \mathrm{Q}_{3}$ and $\mathrm{Q}_{4}$ silicon sites occur with 10, 57 and $33 \%$, respectively, as determined using integration of the CP spectra obtained from the sample containing $20 \mathrm{mM}$ radicals.

The same sample prepared without any radicals, however, shows slightly different silicon ratios of 8,67 , and $25 \%$ for the signals of same sites. The $\mathrm{Q}_{3}$ signals become more abundant and the $\mathrm{Q}_{4}$ signals become less abundant for the samples prepared without radicals, which indicates that the DNP measurements favor the detection of $\mathrm{Q}_{4}$ signals. For the $90 \mathrm{~nm}$ nanoparticles containing $20 \mathrm{mM}$ radicals, the $\mathrm{Q}_{4}$ sites $(42 \%)$ are slightly more abundant compared to $\mathrm{Q}_{2}(4 \%)$ and $\mathrm{Q}_{3}$ sites (54\%). Interestingly, $90 \mathrm{~nm}$ particles containing $5 \mathrm{mM}$ radicals show an increased amount of $\mathrm{Q}_{2}$ signal (12\%), and less intense $\mathrm{Q}_{3}$ and $\mathrm{Q}_{4}$ signals (50 and $38 \%$, respectively), which indicates that a high radical content for the large particles can cause removal of the DNPNMR signals from the $\mathrm{Q}_{2}$ and $\mathrm{Q}_{3}$ surface species.

The direct excitation ${ }^{29} \mathrm{Si}$ measurements on the $90 \mathrm{~nm}$ particles with $20 \mathrm{mM}$ shows significantly different ratios for different silicon signals compared to the $\mathrm{CP}$ spectra. The $\mathrm{Q}_{4}$ signals are present in a much larger ratio $(\sim 83 \%)$. This is also due to the observation of an additional broader $\mathrm{Q}_{4}$ type signal $\left(\mathrm{Q}_{4 \mathrm{~B}}\right)$ by direct excitation (see Fig. 2). However, the $\mathrm{Q}_{2}$ and $\mathrm{Q}_{3}$ signals are much less intense ( $\sim 1$ and $16 \%$, respectively) compared to the CP experiments. The experiments using the sample containing $5 \mathrm{mM}$ radicals show that the $\mathrm{Q}_{2}$ signal is observed with $\sim 1$ to $2 \%$ and the $\mathrm{Q}_{3}$ signal is increased to $\sim 26 \%$, whereas, the $\mathrm{Q}_{4}$ signal decreases to $\sim 73 \%$. These results once again indicate that the $\mathrm{Q}_{4}$ sites are buried beneath the surface and their signals are less bleached out in the presence of a large radical content, whereas, the signals of $\mathrm{Q}_{2}$ and $\mathrm{Q}_{3}$ sites are more sensitive to the radical concentration since they appear either on the surface or close to it and are in closer contact with the radicals. The use of longer relaxation delays for the ${ }^{29} \mathrm{Si}$ direct-excitation experiments, such as 50 or 1000 seconds instead of 10 , results in an increase of the narrow $\mathrm{Q}_{4}$ component, whereas, the broad $\mathrm{Q}_{4}$ signal appears to be reduced (SI 5, ESI $\dagger$ ), as a result of different relaxation behavior of these two components. We did not observe a relaxation-delay dependent enhancement change.

The ${ }^{13} \mathrm{C}$ CP spectra recorded for the arginine and lysine functionalized nanoparticles are shown in Fig. 2 (the same spectrum for the pure sample without surface coating is shown in SI 2, ESI $\dagger$ ). With the DNP enhanced spectra (shown in black in Fig. 2), very strong signals are observed, which are absent in the NMR spectra recorded without $\mu \mathrm{W}$ (shown in grey in Fig. 2). The estimated DNP enhancement is $\sim 40$ to 50 for these experiments, without which the NMR signal observation is practically not possible. Signals from the surface-bound arginine and lysine species are clearly seen in the spectra. Moreover, two additional carbon signals were observed, similar to previous studies on mesoporous materials, ${ }^{19}$ which originate from incomplete condensation of the starting material, tetraethylorthosilicate (TEOS), due to fast nucleation of the silica primary particles. ${ }^{58}$ The carbonyl and $C_{\zeta}$ signals appear weaker due to the short CP contact time which was optimized for the detection of aliphatic signals.

\section{The effect of the nanoparticle size and DNP efficiency}

The nanoparticle size has a remarkable effect on the observed DNP enhancements (Fig. 3 and 4 and Table 1). The enhancements decrease by an order of magnitude upon increasing the
A) $100 \mathrm{~nm}$

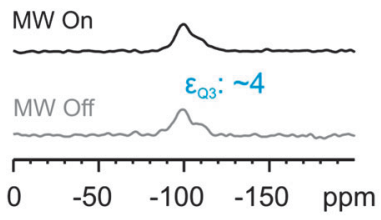

C) $51 \mathrm{~nm}$

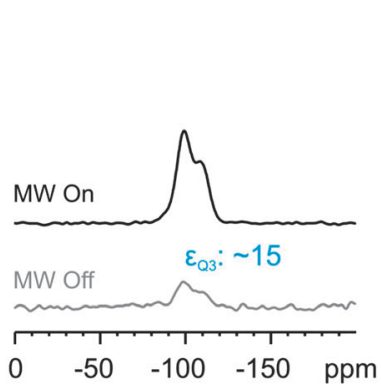

B) $90 \mathrm{~nm}$

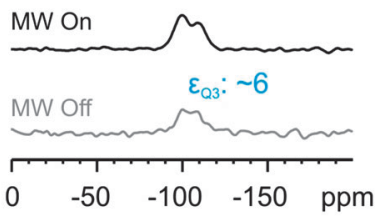

D) $25 \mathrm{~nm}$

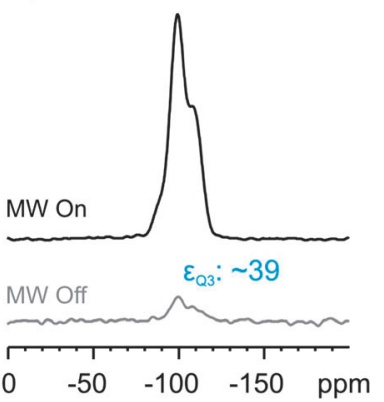

Fig. 3 The effect of the silicon-oxide nanoparticle size on the DNP enhancements $\varepsilon_{29}^{\mathrm{CP}}$ for the particles with diameters of (A) 100 , (B) 90 , (C) 50 , (D) $25 \mathrm{~nm}$. $1{ }^{29} \mathrm{Si}$ CPMAS spectra of arginine functionalized silicon-oxide nanoparticles are recorded with (black, 32 scans) and without (grey, 128 scans) $\mu \mathrm{W}$ irradiation to quantify the proton-DNP enhancements. The spectra were recorded at $\sim 100 \mathrm{~K}$, $9.4 \mathrm{~T}, 8 \mathrm{kHz}$ MAS, and by using samples with a $20 \mathrm{mM}$ TOTAPOL concentration in zirconium oxide rotors. 


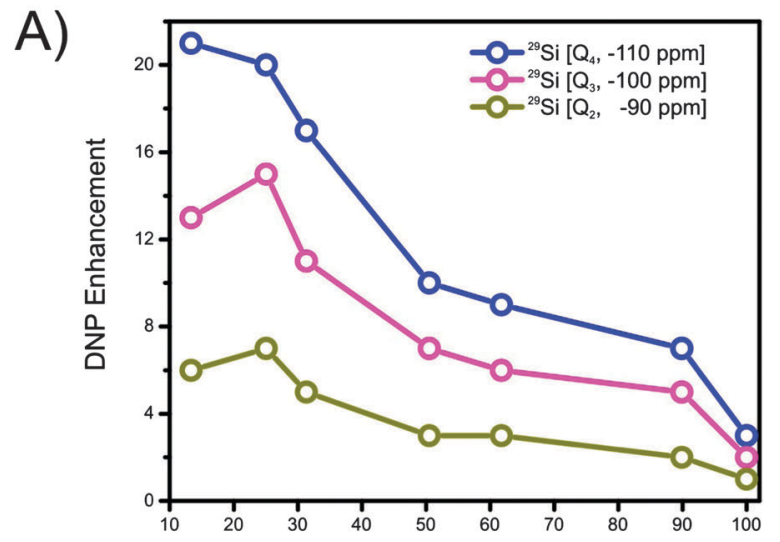

B)

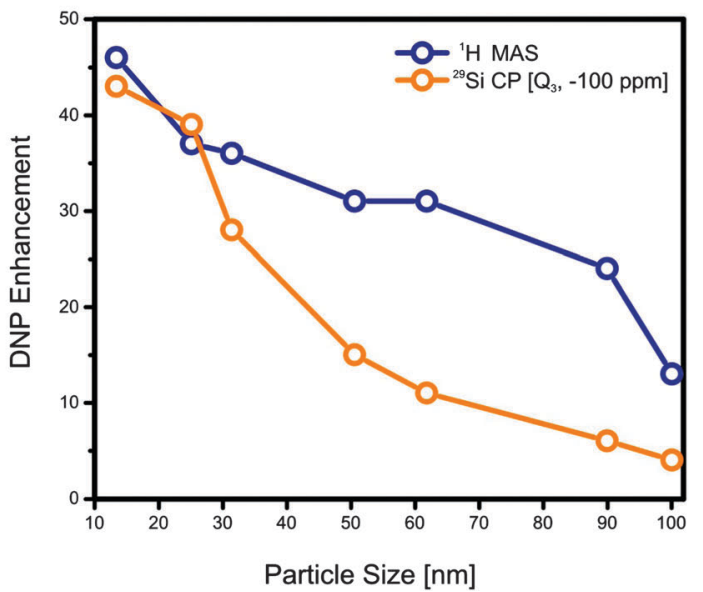

Fig. 4 The effect of silica nanoparticle size on the DNP enhancements measured with (A) ${ }^{29}$ Si direct-excitation and (B) ${ }^{1} \mathrm{H}$ MAS and ${ }^{29}$ Si CP MAS NMR experiments. The data shown are for the arginine coated for 10-90 nm particles, whereas for a pure (non-coated) silica particle for the $100 \mathrm{~nm}$ particle.

particle size from $\sim 10 \mathrm{~nm}\left(\right.$ e.g., $\varepsilon_{29}^{\mathrm{CP}}=43$ and $\left.\varepsilon_{29}^{\mathrm{MAS}} \mathrm{Si}^{\mathrm{P}} \mathrm{Q}_{4}=21\right)$ up to $\sim 100 \mathrm{~nm}\left(\right.$ e.g., $\varepsilon_{29}^{\mathrm{CP}} \mathrm{Si}=4$ and $\left.\varepsilon_{29}^{\mathrm{MAS}} \mathrm{Si}_{4}=3\right)$ in direct-excitation and CP based silicon spectra, respectively. A larger particle size results in a decreased DNP efficiency and a lower enhancement. This phenomenon can be described as follows: All silicon sites can be excited by direct-excitation (core and the surface sites) NMR; however, only a fraction of the atoms can be polarized in DNP-NMR experiments due to limited DNP penetration depth, which in our case can be estimated to be $\sim 4.2$ or $\sim 5.7 \mathrm{~nm}$ (see text below). Consequently, larger than a certain nanoparticle size, there can be a region in the core of the nanoparticle which cannot be polarized but which can be still detected. This decreases the $\mathrm{Si}_{\text {polarized }} / \mathrm{Si}_{\text {non-polarized }}$ ratio, and as a result decreases the apparent DNP enhancements. The direct-excitation silicon experiments show a maximum of DNP enhancements at particle sizes between $\sim 13$ and $25 \mathrm{~nm}$ (Fig. 4). Our data show that, for the ${ }^{29} \mathrm{Si}$ direct-excitation experiments, the penetration depth is not sufficient to polarize all the nuclei above a particle size of $\sim 25 \mathrm{~nm}$. The observed limited DNP penetration depth is also due to a relatively less efficient silicon spin diffusion attributed to the presence of an extended $\mathrm{Si}-\mathrm{O}$ network composed of unlabelled silicon nuclei which also lacks protons, compared to a fully protonated and uniformly carbon labeled protein which has faster spin diffusion. As control experiments, the samples were prepared by using appropriate amounts of radical containing solutions to be able to be sure about the radical concentration on the surfaces of nanoparticles with different surface areas. The results show a similar size-enhancement profile as shown in Fig. 4 (data not shown).

\section{Estimation of DNP penetration depth}

Similar to our "DNP penetration depth" argument, a "spin diffusion barrier" was determined in a recent work by Lafon et al., which describes the extent to which the sub-surface nuclei can be polarized by the radical at the surface of the particle. ${ }^{21}$ A "spin diffusion barrier radius",17,21,59,60 was estimated to be $\sim 35 \AA$ for a mesoporous silica material with an average pore wall thickness of $15 \AA$. Under these conditions all signals were determined to originate from core nuclei and DNP polarization transfer was proposed to bein a direct way. However, due to the larger size of our particles the effect of spin diffusion is sizeable for both silicon and proton nuclei, and there should be a separation of core/bulk nuclei.

In a study performed on 100-200 nm thick GNNQQNY peptide crystals by van der Wel et al. ${ }^{59}$ only a slight decrease $(\sim 25 \%)$ in the proton DNP enhancement was observed when the enhancement of the radical containing solvent and the isolated protein enhancements were compared. The solvent signals show the maximum proton enhancement since the radical polarizes this part first. On the other hand, the protein signals represent an average enhancement since the hyperpolarization diffuses through the crystal, and as a result a polarization gradient occurs with simultaneous detection of highly polarized nuclei which are close to the solvent and less polarized nuclei which are in the core of crystal. Moreover, the effect of spin diffusion is explicitly represented in this work, and it was shown that larger spin diffusion constant leads to a less dramatic DNP enhancement deterioration in a thick sample. We observed a much larger effect of the particle size on the DNP enhancement, which could be a result of much faster spin diffusion in a uniformly labeled and protonated protein crystal, in contrast to our less-proton containing and natural abundance silica nanoparticles. This observation emphasizes the need for a careful optimization of the particle size for obtaining maximum sensitivity.

Moreover, a recent hyperpolarization study was performed on polycrystalline diamond samples by utilizing natural defects as an electron source, ${ }^{61}$ as well as hyperpolarized silicon nano/ micro particles for various purposes including MRI. ${ }^{60,62}$ In the former study by Casabianca et al., polycrystalline diamond samples containing naturally occurring nitrogen-defects as electron sources were studied for different particle sizes and the resulting DNP properties were determined. It has been found that hyperpolarization was only successful for the diamond samples with larger particle sizes, $>100$ to $300 \mathrm{~nm}$ up to microns. Enhancements of up to $15-20$ were observed at $\sim 2 \mathrm{~K}$. Our results indicate an opposite trend, most probably due to our approach involving exogenous radicals in comparison to their approach utilizing intrinsic defects as electron sources. 
In the latter study by Aptekar et al., large silicon nano-micro particles (from $100 \mathrm{~nm}$ up to several microns) were similarly hyperpolarized at $\sim 4 \mathrm{~K}$ leading to sensitive MRI applications. Compared to these studies, our work is unique in the sense of achieving hyperpolarization for much smaller nanoparticles of 10-100 nm, which can lead to more efficient in vivo imaging or molecular targeting applications.

In order to obtain further information on the effect of nanoparticle size to the solvent surrounding the nanoparticles, direct excitation ${ }^{1} \mathrm{H}$ MAS DNP-NMR spectra were recorded. By monitoring the changes in the observed DNP enhancements from the ${ }^{1} \mathrm{H}$ direct-excitation and ${ }^{29} \mathrm{Si} \mathrm{CP}$ NMR experiments, the polarization behavior of the solvent $\left(\mathrm{H}_{2} \mathrm{O}-\mathrm{D}_{2} \mathrm{O}, 10: 90 \% \mathrm{v}: \mathrm{v}\right)$ and the nanoparticle are determined separately (Fig. 4B). A decrease in proton DNP enhancements is observed with increasing nanoparticle size in the ${ }^{29} \mathrm{Si}$ CPMAS experiment, which is explained above by a DNP penetration depth effect. Similarly, a decrease in the proton DNP enhancement of the solvent is then observed with increasing particle size, which cannot be explained with the DNP penetration depth effect due to the readily available radicals in the solvent. In this case, the unfavorably increased radical content in the solvent part of the system might have caused the observation of reduced enhancements for larger particles. We have similarly shown that the ${ }^{1} \mathrm{H}$ DNP enhancement of a uniformly labeled proline sample dissolved in a glycerol-water solvent decreases when the radical concentration is unfavorably increased (above $\sim 25 \mathrm{mM}$ TOTAPOL). ${ }^{28}$

For a control experiment, we performed DNP-NMR experiments on a $90 \mathrm{~nm}$ coated particle by using a four-fold lower radical concentration of $5 \mathrm{mM}$ (Table 1 ). As expected, reducing radical concentration results in slightly lower $\varepsilon_{29}^{\mathrm{MAS}} \mathrm{Si}$ enhancements for the silicon sites compared to the $20 \mathrm{mM}$ sample. The TEOS $\varepsilon_{1}^{\mathrm{MAS}}$, which is inside the nanoparticle, is decreased from 9 to 6-7. Interestingly, lowering radical concentration increases the DNP enhancements detected directly by proton directexcitation NMR and indirectly by silicon CP NMR (from 24 to 32 for the direct and 6 to 8 for the indirect experiment, respectively). This suggests that, a radical concentration of $20 \mathrm{mM}$ is unfavorably high for the surface species as well as for the solvent for the $90 \mathrm{~nm}$ particle size.

\section{A model calculation for determining DNP penetration depth}

A model calculation was performed to analyze the effect of nanoparticle size on the DNP enhancement and to estimate the extent of polarization transfer from the radical into the core regions of the particles (the polarization penetration depth). The total surface area (Fig. 5, black solid line) of the nanoparticles per rotor volume decreases by using larger nanoparticles which, as a result, changes the number of TOTAPOL molecules per unit surface area. In the simplified model, an $\sim 7$ - to 8-fold increase in the apparent radical concentration per unit surface area was observed by increasing the nanoparticle size from $\sim 13$ to $\sim 100 \mathrm{~nm}$ (see SI 7, ESI $\dagger$ for the detailed description of the calculation). The DNP enhancements are obtained from the $\mathrm{CP}$ (red solid line, via $\mathrm{Q}_{3}$ signal) or direct-excitation
A)
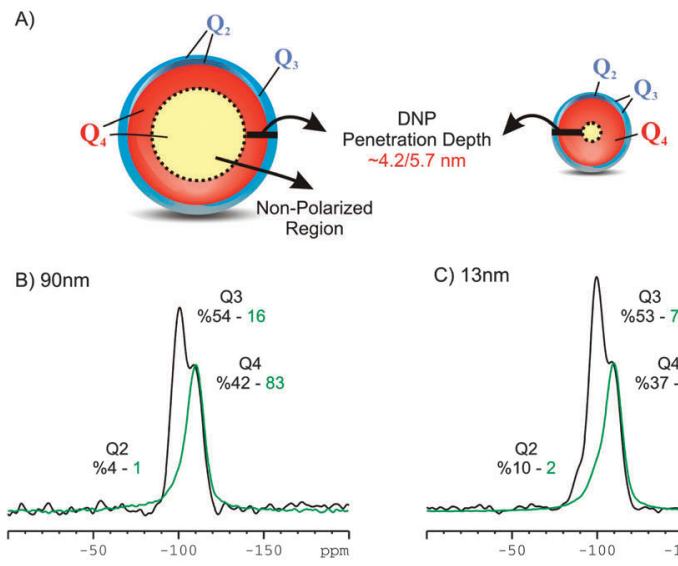

C) $13 \mathrm{~nm}$

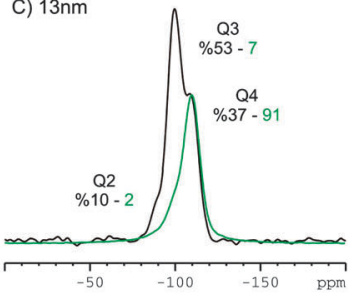

D)

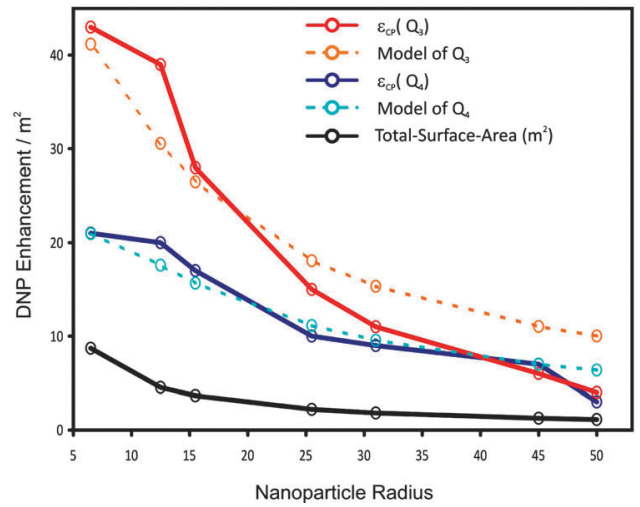

Fig. 5 (A) Representation of the DNP polarization penetration depth in the studied spherical nanoparticles. The $\mathrm{CP}$ and direct-excitation ${ }^{29} \mathrm{Si}$ spectra from the (B) $90 \mathrm{~nm}$ and (C) $13 \mathrm{~nm}$ nanoparticles. (D) The dependence of the ${ }^{1} \mathrm{H}$ (for $\mathrm{Q}_{3}$ signal) and ${ }^{29} \mathrm{Si}$ (for $\mathrm{Q}_{4}$ signal) DNP enhancements to the particle size (solid lines). The fitted size-dependent DNP enhancements for different particle sizes (dashed lines), to estimate an approximate "DNP penetration depth" (see text). The calculated total surface area per-rotor are as well shown in (D) for nanoparticles with different particle sizes.

(blue solid line, via $\mathrm{Q}_{4}$ signal) based ${ }^{29} \mathrm{Si}$ DNP-NMR spectra, (Fig. 5). The dotted lines represent the calculated DNP enhancements for each nanoparticle size which takes the ratio of the polarizable and non-polarizable parts of the nanoparticles into account by using the formula shown in SI 7, ESI $\dagger$ (represented in Fig. 5D). In the ideal case of a sharp border between the polarized and non-polarized regions, the DNP polarization penetration depth is estimated to be $\sim 4.2 \mathrm{~nm}$ when using the enhancement values from CP-based ${ }^{29} \mathrm{Si}$ experiments and $\sim 5.7 \mathrm{~nm}$ when using enhancements from direct-excitationbased ${ }^{29} \mathrm{Si}$ experiments. These values are similar to the ones reported for the mesoporous silica particles. ${ }^{21}$ However they are much smaller than the values obtained from proton-mediated transfer on a fully labeled and protonated protein. ${ }^{59}$ One important point to note here is the presence of residual TEOS species in the nanoparticle, whose carbon signals are observed in ${ }^{13} \mathrm{C}$ CPMAS spectra shown in Fig. 2. The exact position of these moieties is unknown, but a random distribution in the particle core and close to surface is possible. The presence of an additional residual proton bath could have facilitated the polarization transfer 
from the electron to the nanoparticle core throughout the penetration depth of $\sim 4.2 \mathrm{~nm}$ distance (via spin-diffusion), which exceeds the transfer range of a ${ }^{1} \mathrm{H}^{29} \mathrm{Si} \mathrm{CP}$.

\section{DNP polarization build-up time}

DNP polarization transfer from the electrons of the radical to the surrounding nuclei has a characteristic polarization buildup behavior with a time constant $\tau_{\mathrm{B}}$. The magnitude of this time constant can tell about the nature of this process. We determined the polarization build-up times for proton and silicon nuclei by using DNP enhanced ${ }^{29} \mathrm{Si}$ cross-polarization and direct-excitation NMR experiments, respectively (the results are given in Table 1 and shown in Fig. 6). First, we observed two different components in the buildup curves of the $\mathrm{Q}_{4}$ type silicon signals (30 and $70 \%$ population, respectively), which were determined by using saturation-recovery type 1D ${ }^{29} \mathrm{Si}$ MAS DNP-NMR spectra with $\mu \mathrm{W}$ irradiation $\left({ }^{\varepsilon_{\mathrm{B}}-\mathrm{Si}-\mathrm{Q}_{4}}\right.$ and $\left.{ }^{\varepsilon_{\mathrm{B}-F a s t}^{29}} \mathrm{Si}_{4}\right)$. In a recent work by Lafon et al. a similar situation is observed, in which the presence of two different components was explained by the presence of two distinct $\mathrm{Q}_{4}$ silicon sites which are either close to or remote from TOTAPOL. In addition to this, we observed a strong dependence of $\tau_{\mathrm{B}}$ on the
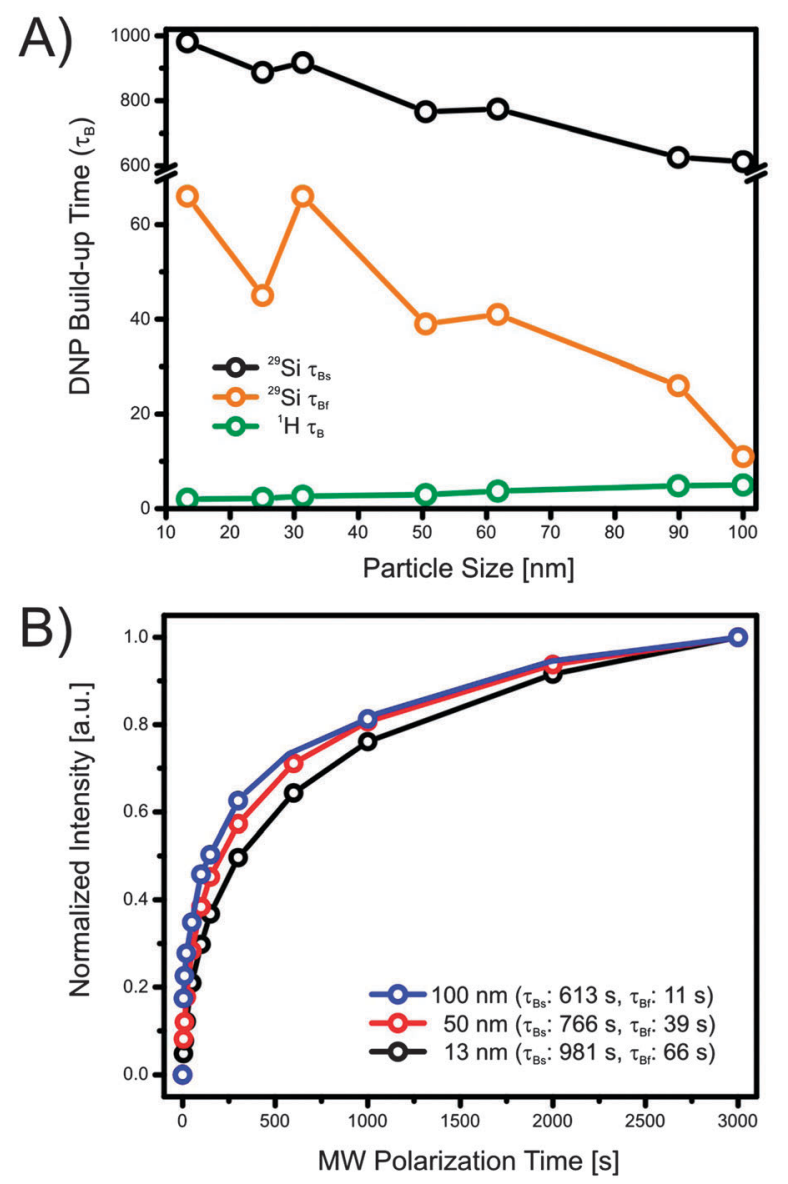

Fig. 6 The effect of the silica nanoparticle size on the DNP polarization build-up times, $\tau_{\mathrm{B}}$. (A) Proton and silicon $\tau_{\mathrm{B}},(\mathrm{B})$ the normalized intensity of the DNP enhanced ${ }^{29}$ Si MAS NMR signals for three selected particle sizes. nanoparticle size. With increasing particle size, the polarization builds up much faster and as a result $\tau_{\mathrm{B}}$ decreases rapidly $\left(\tau_{\mathrm{B} \text {-Fast }}=66 / 11 \mathrm{~s}\right.$ and $\tau_{\mathrm{B} \text {-Slow }}=981 / 613 \mathrm{~s}$ for the $13 / 100 \mathrm{~nm}$ nanoparticles, respectively). As we discussed before, an increase in the particle size results in an increase in the TOTAPOL per-unit-surface-area, and this leads to a faster build-up of the silicon magnetization. The very long build-up times are a result of long longitudinal relaxation times; however, the effect of slow spin diffusion can also contribute to this effect for the very large spherical particles studied which hinders the incorporation of TOTAPOL beneath the surface. On the other hand, a reduced radical concentration slows down the polarization build-up of silicon signals originating from sub-surface regions, and the $\tau_{\mathrm{B}}^{29} \mathrm{Si}^{\mathrm{Q}} \mathrm{Q}_{4}$ for the slow component changes from 626 (for $20 \mathrm{mM}$ ) to 1036 seconds (for $5 \mathrm{mM}$ ).

Narrower silicon lines are observed in $1 \mathrm{D}{ }^{29} \mathrm{Si}$ MAS DNPNMR spectra when longer DNP polarization times are used, similar to the situation observed for the mesoporous materials (see SI 3, ESI $\dagger$ for the ratios of different silicon sites and SI 5, ESI $\dagger$ for the linewidth changes for $\mathrm{Q}_{4}$ site by increased polarization time). ${ }^{21}$ This can be explained by an increase of slow building-up (narrow) of $\mathrm{Q}_{4}$ signals at longer polarization times compared to the fast building-up (broad) one. To quantify this effect, the ratios of the broad and narrow components of the $\mathrm{Q}_{4}$ sites were determined with the ${ }^{29} \mathrm{Si}$ MAS experiments recorded with 10 and 1000 seconds of polarization times for the $90 \mathrm{~nm}$ particle (SI 3, ESI + ). The broad component decreases from 46 to $27 \%$ with increasing polarization time, whereas the narrower component increases from 37 up to $63 \%$.

\section{Conclusions}

In conclusion, we present an application of dynamic nuclear polarization-enhanced solid-state NMR to pure and amino acid functionalized silica nanoparticles of different sizes and low polydispersity. This method allows the ultra-fast and ultrasensitive characterization of pure and arginine/lysine modified silica particles, where such functionalization is important for potential further modification of such nanoparticles and in general for their applications. The surface, core (sub-surface) and the surface-attached species could be probed separately and unique structural information regarding the structure as a function of the depth from the surface could be obtained. Three different Q-type silicon sites $\left(\mathrm{Q}_{2}, \mathrm{Q}_{3}, \mathrm{Q}_{4}\right)$ are determined in the spectra of silica particles. No T-type sites were observed, which indicates an arginine/lysine binding to occur via either hydrogenbonding or electrostatic forces. The DNP properties depend in a remarkable fashion on the particle radius. An enhancement increase of nearly an order of magnitude was observed by decreasing the particle size from $100 \mathrm{~nm}$ down to $13 \mathrm{~nm}$. Surprisingly, the increased particle size resulted in a faster ${ }^{29} \mathrm{Si} \mathrm{DNP}$ polarization buildup time, due to increased surface radical concentration compared to smaller nanoparticles. Different silicon sites were polarized to different extents by performing $\mathrm{CP}$ or direct-excitation based experiments. A DNP penetration depth (or in other words 
spin diffusion barrier) of $\sim 4.2 / 5.7 \mathrm{~nm}$ ( via $^{29} \mathrm{Si} \mathrm{CP} /$ direct-excitation experiments) was estimated by using the particle size dependent DNP enhancements.

The DNP-NMR studies on silica nanoparticles reveal details about polarization efficiency and transfer depending on the particle size. We believe that this knowledge will improve our structural understanding of nanoparticles and DNP processes substantially, and will open up new research directions. In particular, unique information regarding the surface composition and chemistry of nanoparticles becomes accessible using this method, which is essential for the understanding of the structure-function relationship. Only based on such detailed surface structural information rational further developments of nanoparticle functionalization is possible and the DNP-NMR method offers here unique additional insights. Based on such information more efficient delivery systems or catalytically active nanoparticles may be constructed. Furthermore, the efficient hyperpolarization of small silica nanoparticles with presented efficiency can be utilized in magnetic resonance imaging applications.

\section{Acknowledgements}

UA and HO acknowledge the financial support from Deutsche Forschungsgemeinschaft (grant 05106/12-1 of the DIP program). Financial support by the Deutsche Forschungsgemeinschaft (DFG) in the framework of the IGRTG 1524 (SSNI) is gratefully acknowledged by BA. SÖ acknowledges partial support of the Turkish DPT (The State Planning Organization). Sören Selve from ZELMI at TU Berlin is greatly acknowledged for the TEM images of the nanoparticles.

\section{Notes and references}

1 A. W. Overhauser, Polarization of Nuclei in Metals, Phys. Rev., 1953, 92(2), 411-415.

2 T. R. Carver and C. P. Slichter, Polarization of Nuclear Spins in Metals, Phys. Rev., 1953, 92(1), 212-213.

3 T. R. Carver and C. P. Slichter, Experimental Verification of the Overhauser Nuclear Polarization Effect, Phys. Rev., 1956, 102(4), 975-980.

4 R. G. Griffin and T. F. Prisner, High field dynamic nuclear polarization-the renaissance, Phys. Chem. Chem. Phys., 2010, 12(22), 5737-5740.

5 L. R. Becerra, G. J. Gerfen, R. J. Temkin, D. J. Singel and R. G. Griffin, Dynamic Nuclear-Polarization with A CyclotronResonance Maser at 5-T, Phys. Rev. Lett., 1993, 71(21), 3561-3564.

6 D. A. Hall, D. C. Maus, G. J. Gerfen, S. J. Inati, L. R. Becerra, F. W. Dahlquist and R. G. Griffin, Polarization-enhanced NMR spectroscopy of biomolecules in frozen solution, Science, 1997, 276(5314), 930-932.

7 J. H. Ardenkjaer-Larsen, B. Fridlund, A. Gram, G. Hansson, L. Hansson, M. H. Lerche, R. Servin, M. Thaning and K. Golman, Increase in signal-to-noise ratio of $>10000$ times in liquid-state NMR, Proc. Natl. Acad. Sci. U. S. A., 2003, 100(18), 10158-10163.

8 R. G. Griffin and T. F. Prisner, High field dynamic nuclear polarization--the renaissance, Phys. Chem. Chem. Phys, 2010, 12(22), 5737-5740.

9 T. Maly, G. T. Debelouchina, V. S. Bajaj, K. N. Hu, C. G. Joo, M. L. Mak-Jurkauskas, J. R. Sirigiri, P. C. van der Wel, J. Herzfeld, R. J. Temkin and R. G. Griffin, Dynamic nuclear polarization at high magnetic fields, J. Chem. Phys., 2008, 128(5), 052211.

10 M. Rosay, A. C. Zeri, N. S. Astrof, S. J. Opella, J. Herzfel and R. G. Griffin, Sensitivity-enhanced NMR of biological solids: Dynamic Nuclear Polarization of Y21M fd bacteriophage and purple membrane, Biophys. J., 2001, 80(1), 368A.

11 M. L. Mak-Jurkauskas, V. S. Bajaj, M. K. Hornstein, M. Belenky, R. G. Griffin and J. Herzfeld, Energy transformations early in the bacteriorhodopsin photocycle revealed by DNP-enhanced solid-state NMR, Proc. Natl. Acad. Sci. U. S. A., 2008, 105(3), 883-888.

12 U. Akbey, W. T. Franks, A. Linden, S. Lange, R. G. Griffin, B. J. van Rossum and H. Oschkinat, Dynamic Nuclear Polarization of Deuterated Proteins, Angew. Chem., Int. Ed., 2010, 49, 7803-7806.

13 T. Jacso, W. T. Franks, H. Rose, U. Fink, J. Broecker, S. Keller, H. Oschkinat and B. Reif, Characterization of Membrane Proteins in Isolated Native Cellular Membranes by Dynamic Nuclear Polarization Solid-State NMR Spectroscopy without Purification and Reconstitution, Angew. Chem., Int. Ed., 2011, 2, 432-435.

14 G. T. Debelouchina, M. J. Bayro, P. C. van der Wel, M. A. Caporini, A. B. Barnes, M. Rosay, W. E. Maas and R. G. Griffin, Dynamic nuclear polarization-enhanced solidstate NMR spectroscopy of GNNQQNY nanocrystals and amyloid fibrils, Phys. Chem. Chem. Phys., 2010, 12(22), 5911-5919.

15 A. H. Linden, S. Lange, W. T. Franks, U. Akbey, E. Specker, B. J. van Rossum and H. Oschkinat, Neurotoxin II Bound to Acetylcholine Receptors in Native Membranes Studied by Dynamic Nuclear Polarization NMR, J. Am. Chem. Soc., 2011, 133(48), 19266-19269.

16 M. Afeworki, R. A. Mckay and J. Schaefer, Selective Observation of the Interface of Heterogeneous Polycarbonate Polystyrene Blends by Dynamic Nuclear-Polarization C-13 NMRSpectroscopy, Macromolecules, 1992, 25(16), 4084-4091.

17 M. Afeworki, S. Vega and J. Schaefer, Direct ElectronTo-Carbon Polarization Transfer in Homogeneously Doped Polycarbonates, Macromolecules, 1992, 25(16), 4100-4105.

18 V. Vitzthum, F. Borcard, S. Jannin, M. Morin, P. Mieville, M. A. Caporini, A. Sienkiewicz, S. Gerber-Lemaire and G. Bodenhausen, Fractional Spin-Labeling of Polymers for Enhancing NMR Sensitivity by Solvent-Free Dynamic Nuclear Polarization, ChemPhysChem, 2011, 12(16), 2929-2932.

19 A. Lesage, M. Lelli, D. Gajan, M. A. Caporini, V. Vitzthum, P. Mieville, J. Alauzun, A. Roussey, C. Thieuleux, A. Mehdi, G. Bodenhausen, C. Coperet and L. Emsley, Surface 
Enhanced NMR Spectroscopy by Dynamic Nuclear Polarization, J. Am. Chem. Soc., 2010, 132(44), 15459-15461.

20 M. Lelli, D. Gajan, A. Lesage, M. A. Caporini, V. Vitzthum, P. Mieville, F. Heroguel, F. Rascon, A. Roussey, C. Thieuleux, M. Boualleg, L. Veyre, G. Bodenhausen, C. Coperet and L. Emsley, Fast Characterization of Functionalized Silica Materials by Silicon-29 Surface-Enhanced NMR Spectroscopy Using Dynamic Nuclear Polarization, J. Am. Chem. Soc., 2011, 133(7), 2104-2107.

21 O. Lafon, M. Rosay, F. Aussenac, X. Y. Lu, J. Trebosc, O. Cristini, C. Kinowski, N. Touati, H. Vezin and J. P. Amoureux, Beyond the Silica Surface by Direct Silicon29 Dynamic Nuclear Polarization, Angew. Chem., Int. Ed., 2011, 50(36), 8367-8370.

22 A. J. Rossini, A. Zagdoun, M. Lelli, J. Canivet, S. Aguado, O. Ouari, P. Tordo, M. Rosay, W. E. Maas, C. Coperet, D. Farrusseng, L. Emsley and A. Lesage, Dynamic nuclear polarization enhanced solid-state NMR spectroscopy of functionalized metal-organic frameworks, Angew. Chem., Int. Ed., 2012, 51(1), 123-127.

23 V. Vitzthum, P. Mieville, D. Carnevale, M. A. Caporini, D. Gajan, C. Coperet, M. Lelli, A. Zagdoun, A. J. Rossini, A. Lesage, L. Emsley and G. Bodenhausen, Dynamic nuclear polarization of quadrupolar nuclei using cross polarization from protons: surface-enhanced aluminium-27 NMR, Chem. Commun., 2012, 48(14), 1988-1990.

24 I. V. Sergeyev, L. A. Day, A. Goldbourt and A. E. McDermott, Chemical shifts for the unusual DNA structure in Pf1 bacteriophage from dynamic-nuclear-polarization-enhanced solid-state NMR spectroscopy, J. Am. Chem. Soc., 2011, 133(50), 20208-20217.

25 M. Renault, S. Pawsey, M. P. Bos, E. J. Koers, D. Nand, B. R. Tommassen-van, M. Rosay, J. Tommassen, W. E. Maas and M. Baldus, Solid-State NMR Spectroscopy on Cellular Preparations Enhanced by Dynamic Nuclear Polarization, Angew. Chem., Int. Ed., 2012, 51(12), 2998-3001.

26 L. Reggie, J. J. Lopez, I. Collinson, C. Glaubitz and M. Lorch, Dynamic Nuclear Polarization-Enhanced Solid-State NMR of a(13)C-Labeled Signal Peptide Bound to Lipid-Reconstituted Sec Translocon, J. Am. Chem. Soc., 2011, 133(47), 19084-19086.

27 A. H. Linden, W. T. Franks, U. Akbey, S. Lange, B. J. van Rossum and $\mathrm{H}$. Oschkinat, Cryogenic temperature effects and resolution upon slow cooling of protein preparations in solid state NMR, J. Biomol. NMR, 2011, 51(3), 283-292.

28 S. Lange, A. H. Linden, U. Akbey, W. T. Franks, N. M. Loening, B. J. van Rossum and H. Oschkinat, The effect of biradical concentration on the performance of DNP-MASNMR, J. Magn. Reson., 2012, 216, 209-212.

29 U. Akbey, A. H. Linden and H. Oschkinat, High-Temperature Dynamic Nuclear Polarization, Appl. Magn. Reson., 2012, 43(1-2), 81-90, DOI: 10.1007/s00723-012-0357-2.

30 P. L. Stiles, J. A. Dieringer, N. C. Shah, R. R. Van Duyne, Surface-Enhanced Raman Spectroscopy; Annual Reviews: Palo Alto, 2008.

31 A. Campion and P. Kambhampati, Surface-enhanced Raman scattering, Chem. Soc. Rev., 1998, 27(4), 241-250.
32 R. G. Griffin, SPECTROSCOPY Clear signals from surfaces, Nature, 2010, 468(7322), 381-382.

33 Y. F. Lu, Y. Yang, A. Sellinger, M. C. Lu, J. M. Huang, H. Y. Fan, R. Haddad, G. Lopez, A. R. Burns, D. Y. Sasaki, J. Shelnutt and C. J. Brinker, Self-assembly of mesoscopically ordered chromatic polydiacetylene/silica nanocomposites, Nature, 2001, 410(6831), 913-917.

34 H. Y. Fan, K. Yang, D. M. Boye, T. Sigmon, K. J. Malloy, H. F. Xu, G. P. Lopez and C. J. Brinker, Self-assembly of ordered, robust, three-dimensional gold nanocrystal/silica arrays, Science, 2004, 304(5670), 567-571.

35 S. M. Yang, S. G. Jang, D. G. Choi, S. Kim and H. K. Yu, Nanomachining by colloidal lithography, Small, 2006, 2(4), 458-475.

36 C. Burda, X. B. Chen, R. Narayanan and M. A. El-Sayed, Chemistry and properties of nanocrystals of different shapes, Chem. Rev., 2005, 105(4), 1025-1102.

37 G. Schmidt, Nanoparticles: From Theory to Application, Wiley, Heidelberg, 2004.

38 O. Akbulut, C. R. Mace, R. V. Martinez, A. A. Kumar, Z. Nie, M. R. Patton and G. M. Whitesides, Separation of Nanoparticles in Aqueous Multiphase Systems through Centrifugation, Nano Lett., 2012, 12(8), 4060-4064.

39 M. E. Akerman, W. C. W. Chan, P. Laakkonen, S. N. Bhatia and E. Ruoslahti, Nanocrystal targeting in vivo, Proc. Natl. Acad. Sci. U. S. A., 2002, 99(20), 12617-12621.

40 S. Mornet, S. Vasseur, F. Grasset and E. Duguet, Magnetic nanoparticle design for medical diagnosis and therapy, J. Mater. Chem., 2004, 14(14), 2161-2175.

41 X. Gao, Y. Cui, R. M. Levenson, L. W. K. Chung and S. Nie, In vivo cancer targeting and imaging with semiconductor quantum dots, Nat. Biotechnol., 2004, 22(8), 969-976.

42 T. J. Brunner, P. Wick, P. Manser, P. Spohn, R. N. Grass, L. K. Limbach, A. Bruinink and W. J. Stark, In Vitro Cytotoxicity of Oxide Nanoparticles:GÇë Comparison to Asbestos, Silica, and the Effect of Particle Solubility, Environ. Sci. Technol., 2006, 40(14), 4374-4381.

43 M. De, P. S. Ghosh and V. M. Rotello, Applications of Nanoparticles in Biology, Adv. Mater., 2008, 20(22), 4225-4241.

44 T. Yokoi, Y. Sakamoto, O. Terasaki, Y. Kubota, T. Okubo and T. Tatsumi, Periodic arrangement of silica nanospheres assisted by amino acids, J. Am. Chem. Soc., 2006, 128(42), 13664-13665.

45 W. Stober, A. Fink and E. Bohn, Controlled Growth of Monodisperse Silica Spheres in Micron Size Range, J. Colloid Interface Sci., 1968, 26(1), 62-69.

46 F. Blanc, C. Coperet, J. Thivolle-Cazat, J. M. Basset, A. Lesage, L. Emsley, A. Sinha and R. R. Schrock, Better characterization of surface organometallic catalysts through resolution enhancement in proton solid state NMR spectra, Inorg. Chem., 2006, 45(23), 9587-9592.

47 P. Avenier, A. Lesage, M. Taoufik, A. Baudouin, A. De Mallmann, S. Fiddy, M. Vautier, L. Veyre, J. M. Basset, L. Emsley and E. A. Quadrelli, Well-defined surface imido amido tantalum(v) species from ammonia and silica-supported tantalum hydrides, J. Am. Chem. Soc., 2007, 129(1), 176-186. 
48 M. M. Demir, K. Koynov, U. Akbey, C. Bubeck, I. Park, I. Lieberwirth and G. Wegner, Optical properties of composites of PMMA and surface-modified zincite nanoparticles, Macromolecules, 2007, 40(4), 1089-1100.

49 M. M. Demir, P. Castignolles, U. Akbey and G. Wegner, In-situ bulk polymerization of dilute Particle/MMA dispersions, Macromolecules, 2007, 40(12), 4190-4198.

50 O. Tunusoglu, R. Munoz-Espi, U. Akbey and M. M. Demir, Surfactant-assisted formation of organophilic $\mathrm{CeO}_{2}$ nanoparticles, Colloids Surf., A, 2012, 395(0), 10-17.

51 O. Lafon, A. S. L. Thankamony, M. Rosay, F. Aussenac, X. Lu, J. Trebosc, V. Bout-Roumazeilles, H. Vezin and J. P. Amoureux, Indirect and direct ${ }^{29} \mathrm{Si}$ dynamic nuclear polarization of dispersed nanoparticles, Chem. Commun., 2013, 49(28), 2864-2866, DOI: 10.1039/c2cc36170a.

52 T. Kobayashi, O. Lafon, A. S. Lilly Thankamony, I. I. Slowing, K. Kandel, D. Carnevale, V. Vitzthum, H. Vezin, J. P. Amoureux, G. Bodenhausen and M. Pruski, Analysis of sensitivity enhancement by dynamic nuclear polarization in solid-state NMR: a case study of functionalized mesoporous materials, Phys. Chem. Chem. Phys., 2013, 15(15), 5553-5562, DOI: 10.1039/c3cp00039g.

53 A. J. Rossini, A. Zagdoun, F. Hegner, M. Schwarzwälder, D. Gajan, C. Coperet, A. Lesage and L. Emsley, Dynamic Nuclear Polarization NMR Spectroscopy of Microcrystalline Solids, J. Am. Chem. Soc., 2012, 134(40), 16899-16908.

54 B. Altin, Synthesis and characterization of monodisperse silica based functional nanoparticles for multi-purpose applications, Master of Science, Izmir Institute of Technology, 2009.

55 C. S. Song, K. N. Hu, C. G. Joo, T. M. Swager and R. G. Griffin, TOTAPOL: A biradical polarizing agent for dynamic nuclear polarization experiments in aqueous media, J. Am. Chem. Soc., 2006, 128(35), 11385-11390.

56 R. Michel, PhD thesis, TU Berlin, 2013.

57 O. Lafon, A. S. L. Thankamony, T. Kobayashi, D. Carnevale, V. Vitzthum, I. I. Slowing, K. Kandel, H. Vezin, J. P. Amoureux, G. Bodenhausen and M. Pruski, Mesoporous Silica Nanoparticles Loaded with Surfactant: Low Temperature Magic Angle Spinning ${ }^{13} \mathrm{C}$ and ${ }^{29} \mathrm{Si}$ NMR Enhanced by Dynamic Nuclear Polarization, J. Phys. Chem. C, 2012, 117(3), 1375-1382.

58 D. L. Green, J. S. Lin, Y. F. Lam, M. Z. C. Hu, D. W. Schaefer and M. T. Harris, Size, volume fraction, and nucleation of Stober silica nanoparticles, J. Colloid Interface Sci., 2003, 266(2), 346-358.

59 P. C. A. van der Wel, K. N. Hu, J. Lewandowski and R. G. Griffin, Dynamic nuclear polarization of amyloidogenic peptide nanocrystals: GNNQQNY, a core segment of the yeast prion protein Sup35p, J. Am. Chem. Soc., 2006, 128(33), 10840-10846.

60 A. E. Dementyev, D. G. Cory and C. Ramanathan, Dynamic nuclear polarization in silicon microparticles, Phys. Rev. Lett., 2008, 100(12), 127601.

61 L. B. Casabianca, A. I. Shames, A. M. Panich, O. Shenderova and L. Frydman, Factors Affecting DNP NMR in Polycrystalline Diamond Samples, J. Phys. Chem. C, 2011, 115(39), 19041-19048.

62 J. W. Aptekar, M. C. Cassidy, A. C. Johnson, R. A. Barton, M. Lee, A. C. Ogier, C. Vo, M. N. Anahtar, Y. Ren, S. N. Bhatia, C. Ramanathan, D. G. Cory, A. L. Hill, R. W. Mair, M. S. Rosen, R. L. Walsworth and C. M. Marcus, Silicon nanoparticles as hyperpolarized magnetic resonance imaging agents, ACS Nano, 2009, 3(12), 4003-4008. 